U. S. BUREAU OF EDUCATION BULLETIN, 19:6, NO. 4

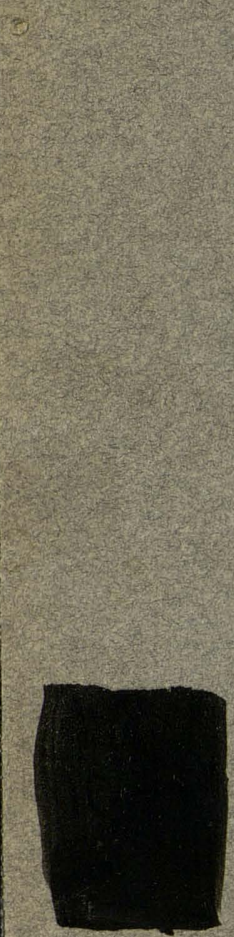


TEXAS TECH UNIVERSITY

3 1295025531657 


\section{DEPARTMENT OF THE INTERIOR}

BUREAU OF EDUCATION

BULLETIN, 1926, No. 24

\section{AN OUTLINE OF METHODS OF RESEARCH WITH SUGGESTIONS FOR HIGH SCHOOL PRINCIPALS AND TEACHERS}

\section{Natl . сомmітte on Research in Sed. Ed.}

P. W. L. COX, New York University, New York

JOSEPH G. MASTERS, Principal, Central High School, Omaha, Nebr.

JOHN K. NORTON, Director of Research Division, National Education Association, Washington, D. C.

RALPH W. PRINGLE, Principal, University High School, Illinois State Normal University, Normal, Ill.

ARTHUR J. JONES, University of Pennsylvania, Philadelphia, Pa., Chairman.



UNITED STATES

GOVERNMENT PRINTING OFFICE WASHINGTON

1927

\$228-263 
ADDITIONAL COPIES

OF THIS PUBLICATION MAY BE PROCURED FROM THE SUPERINTENDENT OF DOCUMENTS GOVERNMENT PRINTING OFFICE WASHINGTON, D. C.

$$
\text { AT }
$$

10 CENTS PER COPY 


\section{CONTENTS}

Letter of transmittal

National Committee on Research in Secondary Education _..._..... vI

I. Introduction

1. The need for educational research 1

2. The teacher as a research worker. 2

3. The obstacles in the way of research

4. The purpose of the bulletin 3

II. Conditions essential to scientific research__ 3

1. The meaning and purpose of research 3

2. Research, a method__._. 5

3. The elements in research

4. The "pure" research and "practical" research worker____-_ 9

5. The need for reinvestigation of research problems_______- 10

III. The qualifications of the research worker

IV. Types of research problems

1. The historical type___ 12

2. The experimental type

3. The philosophical type_.. 16

4. The survey type 18

V. The questionnaire

VI. The report__-_- 25

VII. Summary of suggestions and directions

VIII. Research agencies available for the principal and teacher-_-_-_-_ $\quad 27$

IX. Bibliography 



\title{
LETTER OF TRÁNSMITTAL
}

\author{
DepartMent OF THE INTERTOR, \\ Bureau of Education, \\ Washington, January 20, 192\%.
}

SIR: This bulletin is the second of a cooperative series sponsored by the National Committee on Research in Secondary Education. With the profession of education demanding research as a basis for adaptation of school procedures, research is being undertaken by an increasing number of agencies and is rapidly involving school principals and classroom teachers. The Bureau of Education regards this tendency as wholesome and is seeking to encourage it by lending its facilities for research to educational organizations.

It is believed that this bulletin will prove helpful to high-school principals and teachers who wish to undertake research concerning their problems and will encourage them to undertake research.

Jno. J. Tigert, Commissioner.

The Secretary of the Interior. 


\section{NATIONAL COMMITTEE ON RESEARCH IN SECONDARY EDUCATION}

\section{Organization representatives:}

E. J. Ashbaugh, Educational Research Association.

Francis M. Crowley, National Catholic Welfare Conference.

R. N. Dempster, National Association of Collegiate Registrars.

J. B. Edmonson, North Central Association of Colleges and Secondary Schools.

Ralph E. Files, Association of Colleges and Secondary Schools of the Middle States and Maryland.

Francis M. Froelicher, Progressive Education Association.

J. C. Hanna, National Association of High School Inspectors and Supervisors.

A. J. Jones, National Society of College Teachers of Education.

Leonard V..Koos, National Society for the Study of Education.

C. W. Newhall, Private School Association of the Central States.

J. K. Norton, National Education Association.

J. Orin Powers, Phi Delta Kappa.

Horace M. Rebok, California Society for the Study of Secondary Education.

W. R. Smithey, Association of Colleges and Secondary Schools of the Southern States.

Morton Snyder, Head Masters' Association.

Ph. Soulen, Northwest Association of Secondary and Higher Schools.

Jno. J. Tigert, United States Bureau of Education.

Wm. A. Wetzel, National Association of Secondary School Principals.

E. E. Windes, United States Bureau of Education.

Members at large:

W. B. Bliss, State Department of Education, Ohio.

Thomas Briggs, Teachers College, Columbia University.

George S. Counts, of Chicago University.

J. B. Davis, Boston University.

Emery N. Ferriş, Cornell University.

- James M. Glass, State Department of Public Instruction, Pennsylvania.

W. C. Reavis, University of Chicago.

Joseph Roemer, University of Florida.

Officers:

J. B. Edmonson, chairman.

W. R. Smithey, vice chairman and treasurer.

E. E. Windes, secretary.

Executive committee:

E. J. Ashbaugh.

H. V. Church.

George S. Counts.

J. B. Edmonson.

E. N. Ferriss.

James M. Glass.

A. J. Jones.

J. K. Nortou.

W. R. Smithey.

Wm. A. Wetzel.

E. E. Windes. 


\title{
AN OUTLINE OF METHODS OF RESEARCH
}

\author{
WITH SUGGESTIONS FOR HIGH-SCH0OL PRINCIPALS AND TEACHERS
}

\section{INTRODUCTION}

1. The need for educational research.-One of the most persistent criticisms of education as a science is that it is based too largely on speculative philosophy; it is a matter of opinion, of trial and error, of personal judgment, where one man's opinion is considered as good as another's. Consequently, the business man, the parent, the man on the street often feels that his opinion on school matters is as good as that of anyone else. The teacher, the principal, the superintendent are often looked upon as theorists, with little, if any; understanding of life as it really is. This stage in the development of education is rapidly passing. The fact that it is passing is due largely to the widespread interest in research into educational problems of all kinds. Research aims to discover truth; it is not satisfied with a priori reasoning, nor with subjective judgments, nor with mere speculation based upon insecure and unproved data. Educators everywhere are looking for facts, for truths upon which to base educational reforms. They want to know whether the new method actually brings better results, not what some advocates think it will do. They want to know whether the 60-minute supervised study period actually improves the quality and quantity of the pupils' achievement as compared with the old 45-minute recitation period, and, if so, under what circumstances.

True progress can come only when ways and means of finding facts and measuring results are devised. This is especially true of education because it is so complex and the results are so often delayed. Educators have so long merely "carried on" and followed in the footsteps of those that have gone before that they take it for granted that the objectives set up are actually accomplished, when they really are very much in the dark about what is going on and have no adequate means of knowing what the results are.

This attitude of mind that relies upon tradition and authority, combined with the complexity of the problem, has served to delay the scientific search for truth in education. While scientific research in education has not progressed very far, at least two things have been accomplished: (1) The importance of the discovery of truth has been demonstrated, and (2) methods of finding the truth have been partially developed. 
2. The teacher as a research worker.-Up to the present time educational research, in common with other forms of truth finding, has been confined largely to the laboratory, to places where data could be assembled, dissected, and analyzed apart from the schoolroom, and certain conclusions reached that were sent back to the schoolroom for use. In the psychological laboratory various experiments have been made to find what method of memorizing is the most effective. The results showed that the method of memorizing. a selection as a whole was much more effective than the old one of learning it in parts. The expert comes to the school and obtains certain facts about attendance, costs, methods of instruction, teachers, etc. He takes these to his workroom, his laboratory, analyzes them, and makes his recommendations for improvements. This will always remain a very important part of the machinery of research in education. Certain problems can best be investigated in a place apart where conditions can be absolutely controlled. Every school system should have access to such an agency. The rapid development of Bureaus of Educational Research in our large cities and in many of the teacher-training institutions shows that the importance of this service is now being recognized.

But helpful and indispensable as laboratory research is, by its very isolation it can not carry on certain types of investigation, nor reach valid conclusions regarding all kinds of schoolroom practices. Of necessity these laboratory experiments are usually performed on selected groups, often of adults, and use material unlike that employed in the classroom in which the particular element under investigation is to be found. Data taken away from the school by the expert are analyzed out of relation to actual conditions of the classroom. Much research can be carried on only in the classroom where the process of education is actually taking place, where the conditions are normal, and where all the agencies concerned are functioning as they usually do. In many ways it is this kind of research that promises the largest returns for improvement of practice. Examples of such research problems for the classroom are: (1) Which of these two methods is more effective in reducing tardiness, keeping in after school those who are tardy or making the first period in the morning very attractive? (2) Are the results in actual achievement greater when some time is given to teaching pupils how to study than when they are thrown on their own resources? (3) Do pupils gain appreciably more from five periods a week than from four if the same content and methods are used and other things are equal?

The teacher and the principal, then, become very important factors in educational research. In the near future they must assume their proper share of this responsibility. Principals should develop in 
themselves an attitude of scientific research toward the problems that confront them and do all in their power to develop the same attitude in their teachers.

3. Obstacles in the way of research by the teacher and principal.There are many obstacles in the way of research on the part of the teacher and of the principal. One of these is lack of time and energy for the work. The teaching load carried by teachers is often so great as to preclude any possibility of time for research. Principals and boards of education are still too often obsessed by the traditional factory point of view. The teaching load is stated in terms of the number of recitations held per day or per week. "Vacant periods" are so much lost time, as far as the school is concerned. The principal is often so loaded up with petty duties that could be performed as well, and often better, by a secretary that he has no time to find the truth about the school.

Probably the greatest deterrent to research in the school is the fact that principals and teachers do not know how to do it. Many teachers are eager to try out some plan, to investigate some phase of school work, but they do not know how to begin; they have no conception of the difficulties involved nor of the conditions that must be established in order to make sure that the data are accurate and the conclusions valid. Many otherwise splendid investigations made by teachers and principals are made valueless because conditions essential to research are disregarded. Unfortunately, these often find their way into reputable educational journals, and teachers are often confused or led astray by conclusions or recommendations based upon them.

4. The purpose of this bulletin.-The purpose of this bulletin is to give definite help to the principal and teacher who wish to investigate some phase of secondary school work. The conditions essential to scientific research will be briefly stated in language as nontechnical as possible, and certain types of research problems will be briefly disçussed. Finally, some helps will be given on the method of reporting the results of research.

\section{THE CONDITIONS ESSENTIAL TO SCIENTIFIC RESEARCH}

1. The meaning and purpose of research.-Research is not merely a search for truth; it involves a systematic, purposeful search for truth. The difference between looking for truths and research may be crudely illustrated by the different methods employed in searching for a lost article of any kind. Some persons in attempting to find a lost article look here, there, and everywhere with no system and no purpose except to find the thing lost. They go upstairs looking $28018^{\circ}-27-2$ 
in the first places that come into their heads, then downstairs, then upstairs again, often looking over and over again in the same places. They may find the article and often do; they may even find it at once; but whether they find it or not is largely due to chance, and in the long run much time is wasted. Other people confronted with the same situation consider carefully, before they begin to search, where the article was used last, who used it, and where it is likely to be. If some promising clue is discovered by this method, search is made first in places indicated. If no clue is obtained, a systematic search is made, beginning in a room where the article is most likely to be found and thoroughly searching this room before going to the next. This is systematic, purposeful search, using all available data to guide the search. It may be that more time is sometimes consumed in finding the article than under the haphazard method, but in the long run it will bring results much more quickly and surely. Truths have sometimes been discovered by aceident, but most truth has come to light only after painstaking search and investigation guided by scientific methods. In many cases where truth seems to have been discovered by accident it has happened while the investigator was carefully and systematically working on one possible solution to his problem, and his mind was so alert that when the right solution happened to appear he recognized it at once.

The justice of the point of view just stated must be admitted. The danger of limiting investigation to those elements in education that can with our present facilities be objectively measured must be clearly recognized. Acknowledgment should be made that mere hypothesis is valuable even though it may leave to the future the problem of yerification. The conclusion must be accepted that the statistical treatment, mere manipulation of figures, may utterly fail to achieve the desired result; it may serve to conceal truth or even to harbor untruth.

In many school surveys standard achievement tests are given in arithmetic and reading. The results of these are expressed in numerical terms, averages of these are taken, and the work of the teachers in the school is judged by these averages. This is inadequate and incorrect, because (1) these tests do not measure all the valuable results of teaching, and (2) averages obscure the achievement of individuals in the group. Furthermore, no account is usually taken of the native ability of the groups measured. With the stress now being placed upon differentiated curriculum content to suit the varying needs of pupils in different school systems, standard achievement tests will more and more lose their value for any individual school. 
On the other hand, the danger of the subjective judgment of an individual must clearly be recognized when it is not supported by adequate data which are themselves as largely objective as possible. While recognizing the value of hypothesis, it must also be insisted that, wherever possible, research should at least go as far as possible toward verification of hypothesis.

All sustained, systematic investigation or inquiry which seeks facts or their application is, then, research. Although investigations and inquiries concerning educational procedure are largely. inductive, reflective studies that result in new applications of established principles may be included under the term educational research. Any. testing of educational beliefs or theories by their consistency with ascertainable facts is research.

2. Research, a method.-Keeping all these points clearly in mind, let us see just what research implies. It is, first of all, a method of procedure. The difference betwen scientific research and any other method of research for truth is found in the care taken at each step of the process.

Turning to the field of education, it may be said:

The ultimate purpose of all educational research is the discovery of pro. cedures, rules, and principles relating to the various aspects of education. Critical, reflective thinking is.required, in which discovered facts and principles may be utilized, as well as original data. Thus the answering of any question about education by means of critical reflective thinking, based upon the "best" data obtainable, may properly be called educational research. ${ }^{1}$

3. The elements in research.-In general, the steps in research are the same as those in any process of reasoning. They are as follows: (1) The formulation of the problem; (2) the assembly of relevant data; (3) the critical analysis of data; (4) the development of an hypothesis or possible solution; (5) testing the validity of the hypothesis or verification. These are not to be considered as necessarily sequential, but merely as steps necessary at some point in the process of research.

It may be well at this point to call attention to a marked difference of opinion regarding educational research. This difference has to do largely with the data to be used and with the importance of complete verification. Some authorities clearly indicate that the only data admissible in research are objective data, i. e., data that can be weighed and measured by definite standards and scales, and from which all subjective elements are excluded. They give as examples of this the data that form the basis for studies on the weight and height of school children, age-grade classification of pupils, achievement in reading, writing, and arithmetic measured by standard tests. They say that all research should be based upon data of such

${ }^{1}$ Monroe, W. S., and Johnston, N. B. Reporting educational research, p. 8. 
nature that anyone else could take them and come to the same or similar conclusions. Anything else than this is not research. They also affirm that research must verify conclusions.

Opposed to this are many who contend that all data, even those called objective, have their subjective aspects; that purely subjective data based upon the judgments of teachers are valuable, often of even greater value than data that seem to be more objective, since education involves many elements not yet capable of objective determination; that opinions of people are legitimate objects of investigation and are admissible as data. They also affirm that analysis and hypothesis are in themselves research, even without complete verification. They point out the fact that many of our most valuable scientific truths and laws have been the result merely of analysis, of deductive reasoning based upon known truths, reasoning that has gone no further than hypothesis; for example, the research into differentiated content or method for differing ability groups.

This may be illustrated by a simple example. Suppose a principal is interested in investigating the effect of after-school and Saturday employment upon the work of students in the high school. Taking the elements given on page 5 , scientific research begins by a careful statement of the problem. It acts on the principle that a problem carefully stated is more than half solved. General terms will not suffice. Care is taken to single out the item to be investigated and to state it clearly and concisely, excluding all irrelevant problems that may be interesting in themselves but do not bear on the item to be investigated. We might state our problem as "How does the out-of-school life of the student affect the school?" This is altogether too general to be useful as a topic of investigation. It might include condition of the home, attendance at dances, movies, church, etc., as well as employment. The words "affect the school" might include attendance, school activities, school spirit, as well as scholastic standing; it might also include the effect upon the teacher and other students. A much better statement would be "What is the effect upon the scholastic standing of the students of after-school and Saturday employment?" This is much more specific and omits many irrelevant things. Possibly a still better statement would be "How does the scholastic standing of students who spend no time in employment after school and on Saturdays compare with that of students who spend varying amounts of time in such employment?" Here the causal relationship is entirely omitted, and the question correspondingly restricted. Another source of error would be eliminated if the term "employment" were clearly defined. Does it mean for wages only or should work at home where no wages are given be included? 
Next, great care is taken in the assembly of data. Whatever data are taken, whether objective or subjective, they are subjeeted to rigorous criticism and analysis in order to discover whether they are accurate, whether they are the best obtainable, and whether they are relevant to the problem under investigation. Research of this kind involves first-hand inquiry, actual contact with facts. Very definite methods have been formulated for determining the accuracy and validity of data.

In the problem stated it is by no means easy to secure reliable data. The reports of teachers regarding out-of-school employment are very unreliable. Statements of students from memory of time spent are also unreliable. Probably the best method is to select a given week or month or a period during which a scholastic mark is given and have each student report each day or week the exact amount of time he has spent in employment. This is difficult to secure and even then is inaccurate unless checked up by reference to employers and parents under whom the work has been done. Again, it is not always easy to secure reliable scholastic marks for the period under consideration. These should be taken from the official records of the schools and not from the teacher's memory of these records.

After the data are assembled, they are analyzed with extreme care in order to find their bearing upon the problem. All irrelevant material is rejected, no matter how interesting it may be. Other factors that might influence the scholastic standing must also receive attention. A student may be employed in an occupation that permits time for study, as night clerk in a hotel; sickness or worry or social dissipation might affect the school work of a student not employed; the natural ability of each student must be taken into consideration-that is, if the effect of out-of-school employment on marks is to be investigated. Again, it will not be sufficient to group together all who are employed and compare them with the group not employed. The employed group must be analyzed into those employed for various amounts of time, for it may be found that a certain amount of employment has a good effect, while a targer amount has a bad effect upon school marks. Care must also be exercised that a time of year be taken for the study that is free from undue disturbance due to holidays, final examinations, or the like.

After this careful analysis comes the formation of an hypothesis or tentative conclusion. This involves freeing the mind from prejudice, so that, uninfluenced by tradition or personal bias, the tentative conclusion may be the result of the data obtained. No preconceived ideas or prejudices are allowed to have any influence. The habit of suspending judgment until all the evidence is in must be formed. Jumping at conclusions from inadequate grounds is not tolerated. 
The teacher may believe that students should give their entire time to school work and believe that out-of-school employment is harmful. On this account he may unconsciously put more weight upon certain data that tend to prove this opinion and less upon those opposed to it. Scientific research never starts out to prove anything; it may start out to see whether a certain hypothesis is true or not, but its object is not to prove it true or untrue; it is merely to find what is true.

The hypothesis resulting from the study described should usually be stated thus: "The relationship between the scholastic standing and after-school employment of the students in -..--.--- high school, investigated in the month of _..-...---, 192 , is as follows:" (Here the definite facts are given in detail.) "This seems to indicate that in this school out-of-school employment for _...... hours a week has a stimulating effect upon the scholastic standing of the students." Even here the tentative conclusion stated is questionable; merely because the group of students who were employed ...-..hours had better marks than those who were not employed and than those who were employed other lengths of time would not prove a causal relationship. It might happen that they were superior in native equipment; or the same force, possibly ambition, that led them to seek employment would also cause them to secure better scholastic marks. Such an investigation should attempt to eliminate all of these possible variables. This may be done by giving initial tests that will show the relative intelligence of the two groups, their scholastic standing when the experiment began, and, if possible, any differences in ambition that exist.

Nor is the research worker content with the mere statement of the tentative conclusion. Wherever possible, he attempts to find whether his hypothesis is correct by the process of validation, of trying it out in as many situations as possible to see whether it works. It should be followed up with other groups of students in other years, in a variety of schools and with a variety of methods. Even then a true scientist usually considers the conclusion as tentative, as merely a working hypothesis that will be used until a better one can be found.

This, then, is the essence of research. It is a method that takes nothing for granted, that subjects every fact, every step to careful scrutiny before its acceptance, and absolutely rejects any substitute for the best fact, the best data obtainable. It keeps an open mind; it is free from prejudice; it cultivates the habit of suspended judgment, and accepts any conclusion merely as tentative, valid only so long as it bears the test of trial. 
4. Pure research and "practical" research.-Charters ${ }^{2}$ has called attention to a very important difference between the steps necessary for a pure research worker and those required of what he designates: as the "practical" research worker. It will be helpful to state these differences briefly.

The pure research worker may select his problem from any field without regard to the possible usefulness of its solution or to the practical bearing of the problem itself. After selecting the problem his sole concern is its solution by scientific methods. He is in no way concerned with its practical application. His motto is "truth for truth's sake."

The practical research worker is profoundly concerned with the selection of the problem itself. He first looks over his establishment (his school or class) and finds some weakness or inadequacy, something that he wishes to improve. From this he selects sonie aspect as a problem for research. Having selected it he uses the same methods for its solution as those employed by the pure research worker.

While the pure research worker stops with the solution, the practical research worker is not contented with this as a final stop. "Pure" research workers frequently seek to apply their "pure" results to very mixed practical situations, with dire results to the unwary. Having started with the purpose of improving his school, he must, after he has arrived at a possible solution, actually install it in the school and see how it works. This will often call for modi. fications due to conditions of the school plant, lack of money, or peculiarities of personnel. Educational philosophy to the pure research worker is incidental. To the practical research man it is all essential, far more important than research method; for the setting of the problem, the formulation of the hypothesis, the interpretation of results, and the application of these results to the school situation involve expediency and depend upon philosophy. (This is in reality merely a part of step 5-verification, see page 5 involved in the solution and not a separate step.) In other words, the practical research worker in arriving at a solution must take continually into consideration the practical situation in the place where the improvement is to be made. The final step that'must be taken by this type of research worker is that of maintaining the improvement so that it will become a permanent part of the system. It is very important for principals and superintendents to keep these distinctions continually in mind. The object of their research should always be

${ }^{2}$ Charters, W. W.: Pure research and practical research (Jour. of Ed. Resparch; $12: 95-101$, Sept., 1925). 
improvement of procedure, and they must recognize that they are primarily responsible for seeing that such improvement is actually made.

Strictly speaking, the last step stated by Charters is not a step in research as research, but it is an important duty and function of the practical research worker in the field of education. By this it is not meant that the research worker, if he is a teacher, has the entire responsibility of seeing that the improvement is actually made; this must be done in cooperation with the principal and other teachers. It does emphasize the fact that one who has worked out the solution is usually in the best position to see that the solution is actually incorporated into the structure and organization of the school.

Education provides ample opportunity for both types of research, the pure and the applied. There are so many weak places and inadequacies in all schools that it would seem the part of wisdom for the principal and teacher to stress the practical side of research, leaving the field of pure research, perhaps, to those who are spending their entire time in advanced study.

5. The need for reinvestigation of research problems.--One of the greatest needs in educational research to-day is for reinvestigation of some problems that have already been investigated by some research worker. Education is badly in need of verification of con. clusions formed on the basis of single studies. There are so many possibilities of error in securing data, the conditions are often so complex, the data themselves so imperfect, that conclusions can not be considered in any way as final.

Probably one of the greatest services that a high-school principal or teacher can render is to take some study already made and carefully duplicate it in purpose and method under conditions somewhat different from those of the original study. This will be the best method of getting intimately acquainted with real methods of research and at the same time of performing a very real service to education.

\section{THE QUALIFICATIONS FOR THE RESEARCH WORKER}

From the foregoing discussion it must be apparent that all teachers are not fitted to do research work. Fitness for such work is partly a matter of native endowment and partly a matter of training. Those who do not have the natural endowment or the training should not attempt it.

- In our enthusiasm over the possibilities of research in education we have perhaps attempted to make scientific workers of too many people who are unfitted by nature, temperament, and general education. ${ }^{3}$

s Briggs, T. H.: Problems in secondary education that need solution (School Life, XI : 117, Feb., 1926). 
Courtis ${ }^{4}$ has summed up the qualifications of a research worker as follows:

1. Emotional factors-Drive.

One can not do successful research work unless $(a)$ he has the urge that comes from curiosity, $(b)$ he takes pleasure in self-expression, in creation, (c) he feels that such work will be of real value either to himself or to others.

2. Knowledge-Efficiency.

No one is ready to do effective research until he has developed the following:

(a) Ability to find quickly, to select, and to utilize the results of previous research.

(b) Knowledge of and facility in using approved experimental procedures, inductive and deductive processes, logic and experimentation.

(c) Skili in using approved educational measuring instruments.

(d) Skill in analytical methods, statistical and graphic.

(e) Ability to generalize, to know when and how to make safe generalizations.

( $f$ ) Skill in verification involving criticism and prediction:

( $g$ ) Ability to select and organize the materials used in the investigation and to report the methods and results.

3. Volition-Control.

The volitional factors necessary may be outlined as follows:

(a) Visible evidence.

(1) Courage.

(2) Persistence.

(3) Open-mindedness.

(4) Humility.

(5) Faith.

(b) General powers. ${ }^{5}$

(1) Self-direction-Independence in thought.

(2) Self-appraisal-Power to know one's strength and limitations,

(3) Self-control-Power of self-control.

(c) Convictions.

(1) About nature-Unity of law, evolution, cause and effect.

(2) About self-Potentialities, social consciousness, control of self.

(3) About opportunity-Reality and poss:bility of discovery of truth, possibilities of growth in self and progress of society.

It will be helpful for each one who desires to begin research to examine this suggestive outline and make some attempt at selfappraisal in order to find whether he has the necessary personal equipment to insure success in his undertaking. An interesting outline for such self-appraisal is given by Carl E. Seashore in an open letter to seniors, published by the National Research Council. ${ }^{6}$

* Courtis, S. A. : The development of ability in research (Studies in Education, Year. book No. $X V$, the Nat. Soc. of College Teachers of Ed., 85 pp., 1926). Adapted.

5 To this list of powers given by Courtis we might well add "common sense."

- This may be obtained by communicating with the National Research Council, Wash. Ington, D. C. Another helpful list has been compiled by Milton Fairchild from replies received from "scientists studying inanimate nature." This may be obtained by writing Milton Fairchild, The Character Education Institution, U. S. A., 3770 McKinley Street (Chevy Chase), Washington, D. C.

$$
28018^{\circ}-27-3
$$




\section{TYPES OF RESEARCH PROBLEMS}

There are many kinds of research problems that present themselves to the teacher and the administrator that are well worth investigating. These vary somewhat in their method of attack and their technique. While there is often no clear and sharp line of demarkation between them, four types of problems may, for our present purpose, be recognized: (1) The historical, (2) the experimental, (3) the philosophical, and (4) the survey. Each of these will be briefly discussed, and the procedures and teehnique peculiar to each will be outlined.

1. The historical type.-This type of research problem deals, as its name indicates, with historical material. It may seek to discover some historical facts or to present in a connected way the development of a certain type of school, for example, "Quaker education in the Colony and State of New Jersey," by Thomas Woody." In this the author seeks to discover the schools established by the Quakers in New Jersey during a certain period, to find what their purpose was, and to present the development in a connected manner. No attempt is made to show their influence upon the establishment or development of public schools. He does show, however, the influences and the beliefs that brought about the establishment of the Quaker schools. Marcus L. Jernegan, in his "Beginnings of publie education in New England," s has practically the same problem. He brings to light the various causes that influenced the establishment of the early colonial schools in New England, discovers and assembles certain facts regarding their establishment, and shows, among other things, the entire lack of positive evidence that the Boston Latin School was really opened in 1635 .

In this type of problem there are certain crucial points of method that are of special importance. The first has to do with the reliability of the source. Anyone who wishes to undertake an historical problem will do well to study earefully the material found in the references under "Historical research," on page 29. By no means all statements that are found in print or in manuscript are reliable. Just because a statement is recorded in the minutes of a school committee or printed in a superintendent's report, it should not be taken as a fact unless it meets the tests laid down. It must be ascertained, in the first place, whether the document itself is gemuine; whether it was written at the time when it is supposed to have been written. If found to be genuine, are the statements of fact records of happenings or of opinions of the writer regarding what happened? This opinion or observation may be valuable, and often

7 Published by the author. Philadelphia, 1923.

${ }^{8}$ School Review, $23: 319-330,361-380$. May and June, 1915. 
is, as corroborative evidence, but it is by no means as valuable as a statement of a fact. The opinion of an eyewitness or contemporary, especially if he is a trained observer, is much more valuable than that of a person who was not an eyewitness and untrained. After all data are in and checked, there is still the problem of proper and legitimate interpretation and inference. Great care must be taken in treating facts as facts and not reading into them other things that; in the light of recent developments, might be expected to have been in the original statements. Great care and rigid integrity should be exercised in dealing with all facts and all inferences. It is not wise to undertake this type of research unless one has been thoroughly trained in its technique or has the advantage of the guidance of expert advice.

Many opportunities will be found for investigations of an historical nature; original material will often be brought to light in cleaning out old closets, basements, and attics. Principals should never allow old reports and records to be destroyed until they have been very carefully looked over to see whether they contain material that may prove of value.

2. The experimental type.-The experimental problem involves the discovery of the effect of a given element. Its method is direct manipulation, working with the given element, and observation. It is not historical, because it deals with a present situation; it actually introduces experimental elements or singles them out, and observes and evaluates outcomes. It is possibly the most difficult form of research to undertake outside of a laboratory, but one that promises the best ultimate returns for the school in the improvement of practice. Its difficulty lies in the problem of isolation of elements, of control of conditions, and of actually determining whether the observed result is or is not the result of the element introduced.

The success of the experiment depends upon the following conditions :

1. Selection of a workable problem.

2. The ability of the experimenter to control conditions so as to keep all factors and elements the same throughout the experiment except the element or elements whose effect is to be studied.

3. Selection and introduction of elements that are not complex but comparatively simple.

4. The ability to measure the changes or results obtained.

Unless these conditions can be reasonably well assured, the time and energy spent on experimentation must largely be fruitless.

These conditions may be illustrated by comparing an experiment in science with an experiment in education. The physicist and the chemist can more easily fulfill these conditions than can the teacher, because of the nature of the forces and elements involved. Suppose 
the investigator wishes to test the effect of different amounts of an acid on a given organism. He provides for uniform conditions by selecting individuals of the given organism that are alike; he keeps the temperature uniform; he prepares the acid so that it shall be of a given purity. He then prepares his different acid strengths and makes repeated tests on the organisms and observes the results. $\mathrm{He}$ has largely controlled the conditions. ${ }^{9}$

It is much more difficult in the educational experiment. Suppose it is desired to test the relative effect on English vocabulary of the method of definitely teaching derivatives in Latin as compared with the ordinary method of translation of Latin sentences 'with no teaching of derivatives. At once the difficulty of securing uniform individuals or equivalent groups upon which to try the experiment arises.

The same group obviously can not be used for the two parts of the experiment, for whichever method is first used will produce some results, and so the group will not be the same at the beginning of each trial. When the attempt is made to secure two groups that are equivalent, differences in mental ability, in English ability, in rate of learning, in outside infuences, etc., appear.

Even supposing that all these can be eliminated, there are still differences in outside influences, home and street, that may cause the given results, rather than the method used in the classroom. There are also differences due to different teachers; or if the same teacher teaches each section, she may not be equally well adapted to the two different methods. Hence the difficulty of securing satisfactory conditions is very great. In such an experiment probably the best method that can be employed is as follows:

1. Select two groups of students that are as nearly alike as possible in year in school, in previous preparation, in mental ability, in comparative number of boys and girls, in size of groups, social background, etc.

2. Give each an initial vocabulary test and an intelligence test.

3. Teach the two groups in exactly the same way except that in one group English words derived from Latin are emphasized and in the other the students are left to themselves to learn the derivatives from the translations and the grammatical work.

4. A final vocabulary test is given to each group.

In both the initial and the final vocabulary test only the words derived from the Latin are considered. In comparing the results of the initial and the final tests two methods are used. One of these compares the two groups as wholes. The total vocabulary gain made

${ }^{\circ} \mathrm{A}$ clear and helpful statement on factors that must be taken into consideration in a control experiment is given by Suhrie, Ambrose L.: The inductive deternination of educational method, pp. 35-40. (Warwick and York, 1915.) See also Bíbliography. 
by the group in which derivatives are taught is compared with that made by the other group. The difference between these represents the advantage of one over the other. If the total gain of the first group is 75 words and of the second is 50 words, the superiority of the first over the second is 25 words. But when individual scores are compared, it is found that there is a tremendous variation in individuals, and conclusions based on group results are not entirely satisfactory.

Hence another method of comparison is used-that of pairing individuals having like characteristics. In this method two individuals of relatively equivalent mental ability and vocabulary are compared with one another and the relative gain of each is taken as an index of the superiority of one method over the other. The final result is the average or median of the gains and losses of the pairs compared. Even this is not entirely satisfactory, for there is no measurement of what the group who gained in English vocabulary lost in the aspects of the course in Latin due to the concentration on specific learning of derivatives as compared with what the other group did not lose. It might well be that such loss would overbalance the things actually gained. Relative values must always be taken into consideration in evaluating and putting into practice results of investigations such as this one. Even though it is so unsatisfactory, this illustration may serve to show something of the difficulties involved in this type of problem.

McCall ${ }^{10}$ describes another method-that of rotation-that can be used to good advantage with two groups. In this type of research work the caution given on pages 12 and 13 should be emphasized. Select for the first experiment some extremely simple thing that has obvious results. After this has been mastered a more complex one may be attempted. An experiment that would be simple and helpful might be the determination of which of two different times for the assigning of a lesson was more effective, at the beginning of the recitation or at the end. First try assigning the next lesson at the close of the recitation period, then after continuing this for a certain length of time try assigning it at the beginning. Care should be taken that the assignments should all be of the same type. Each method should be continued long enough to show certain resultssay for a month or longer. During the time careful notes should be taken of the difficulties involved in assigning the lesson at the particular time, of the effect upon the class in understanding the assignment, in remembering it, and in its usefulness as an aid to study. The comparative achievement of the class during and at the end of each period of time should be carefully noted. All these observa-

${ }^{10}$ McCall, William A.: How to experiment in education, Macmillan, 1023. 
tions should be reduced to writing and the final comparisons of the two methods of assignment should be made from an entirely unprejudiced point of view.

McCall recognizes and describes three methods of experimentation: (1) The one-group method; (2) the equivalent group method; and (3) the rotation method. Definite suggestions are given by him for methods of control of conditions and evaluation of. results. Finally, he states several experimental problems and gives suggestions for their analysis. The teacher who wishes to engage in this type of research should carefully study the suggestions given by McCall before beginning the experiment.

3. The philosophical type.-The philosophical type of research problem was much more common some years ago when the study of education or "pedagogy" was considered merely a branch of philosophy. It still has a very legitimate place in educational research. It is this type of research that Monroe ${ }^{11}$ has in mind when he says:

In my judgment there is urgent need for a type of critical study in the field of secondary education which is not included in the popular concept of educational research, or at least its inclusion is not explicit. The type of studies which $I$ have in mind are deduction rather than induction. For example, a great deal of so-called research has related to supervised study, but a critical examination of the published reports reveals practically nothing concerning the actual procedures that a teacher should employ in directing learning outside of the recitation period. These procedures will not be discovered directly by collecting and tabulating quantitative data. They must be deduced from the laws of learning and the principles of teaching. It is perhaps true that as yet our formulations of these laws and principles are not sufficiently complete, so that the deductions will have a high degree of dependability, but tentative deductions are at least possible. After the procedures which a teacher should employ have been deduced there will, of course, be need for verification, which in some cases should be experimental.

This type of research is probably seen in its purest form in mathematical research, where the investigator sets up a series of postulates and proceeds to analyze these postulates and to develop theorems or systems or draw conclusions. Often no objective data whatever are used, and frequently no practical application of the conclusion is attempted. The accuracy of the research depends upon the validity of the postulates, the accuracy of the analysis, and the particular elements taken upon which the conclusions are based.

This type of research might be used in education for the solution of the problem of the place and function of interest in teaching. This problem might be attacked from the historical point of view alone. If this were done, the problem would be to secure reliable sources of educational practices in the past and the theories of educators in different stages of the history of education. Or it might

${ }^{11}$ Monroe, W. S.: Quoted by Briggs in School Life, 11 : p. 118, 1926. 
be attacked from the experimental point of view and an effort made to determine by actual experiment what are the results of the use of interest in teaching as compared with results when interest is not used.

However, if the problem were investigated by the philosophical method,,$^{12}$ the steps would be-(1) A clear statement of the concept of interest as applied to teaching; (2) an analysis of the concept to determine the various elements involved; (3) the application of each of these elements to the process of teaching to show what elements are likely to be useful and what are not, and to make clear the utility and the limitations of the concept as a whole and each element in particular.

The chief points of difficulty are in the analysis of the concept and in the selection and application of the elements to the process of teaching. It should be said that, even though these difficulties are successfully surmounted, the validity of the conclusions depends entirely upon the accuracy of the original concept or postulate. If this is not valid, then no amount of analysis or of reasoning will bring valid results. Accordingly, extreme care must be taken in selecting and validating the original postulate. In doing this all the methods of historical research may be used or those employed in the survey type of problem may be utilized to discover what the accepted concept or postulate may be. If this is not done, the result will be entirely useless. However, it must be remembered that all postulates and concepts are mere hypotheses, valid only as they stand the test of actual practice. On this account it is sometimes entirely justifiable to accept as a basis for analysis some concept that is not generally accepted. If we took as our basis only such theories or postulates as are generally accepted, no progress would be possible. Progress comes from new ideas, new concepts, new postulates.

Another point should always be kept in mind: Any philosophical research in education should be followed by experimentation to determine the validity of the conclusion and to make clear its application to educational practice.

Another slightly different phase of the philosophical type of research problem is found in the examination of current beliefs to determine whether such beliefs are.warranted in the light of facts and principles that have already been accepted as valid or to determine what modifications must be made in such beliefs in order to make them harmonize with facts and principles. We might take for such a problem the current belief that the junior high school is the school for the adolescent. The first step would be to examine the writings of men who are considered authorities on the junior

${ }_{12}$ See Waples, Douglas: An approach to the synthetic study of interest in education, Warwick \& York, 1921, where a similar method is used. 
high school to see just what their belief is. Having established this and formulated the belief, the next step is to determine by examination of authorities what is meant by "adolescent." Then would come the investigation of facts already known regarding the varying ages when adolescence begins; the distribution of students in various stages of physiological maturity within the various grades of school as they now are; the assembly of facts regarding intelligence levels of students to determine whether all boys and girls can profit by the work of the junior high school as now constituted; the examination of the facts regarding the various achievements of pupils of the same age and stage of physiological maturity; the analysis of facts and opinions regarding what actual differences there are in attitudes and interests between immature and maturing students. After these facts and principles were assembled and analyzed we would be in a position to determine whether this belief that the junior high school is the school of the adolescent is valid. Taking into consideration the variations in the ages of beginning adolescence, the wide range in intelligence levels and achievement in school subjects, we would be in a position to describe modifications in the present elementary and junior high schools, if this belief were really to be accepted.

In this study there have been no new facts brought to light, no new materials presented, but real research has been accomplished in assembling and analyzing facts and materials in the light of a certain belief taken as a basis.

While this method is not often used exclusively in educational research, it occupies an important place in many investigations. Indeed, it might be said that one of the greatest needs of education to-day is this type of research, in order that there may be developed a real philosophy of education that takes into account the most upto-date contributions of modern science.

It also has an important place in the evaluation of certain methods and procedures in the classroom. A good example of this is found in the evaluation of the Dalton and Winnetka plans, by W. H. Kilpatrick. ${ }^{13}$ This type of research problem possesses less value and has more danger for the ordinary research student than any other type of problem described. It should seldom be undertaken by the high-school principal or teacher.

4. The survey type.-The purpose of the survey type of investigation is to describe as accurately, objectively, and quantitatively as possible a class, a school, or a school system-city, State, or National. It usually traces relationships, indicates causes, and suggests improvements. It often employs the historical method in determining

${ }_{18}$ Twenty-rourth Yearbook of the Nat. Society for the Study of Fducation, Part II, pp. 273-277. 
the validity of data and the philosophical method in analyzing objectives and outcomes. By its very nature it makes more frequent use of statistical methods than any other type.

Examples of this type are found in the Colvin and McPhail: "Intelligence of seniors in the high schools of Massachusetts "; ${ }^{14}$ J. H. Kelley's "Teachers' marks, their variability and standardization "; $;^{15}$ O'Brien's "A study of the school records of pupils failing in academic or commercial high-school subjects." 16 This includes the two types described by McCall as "descriptive investigations" and "causal investigations." It may readily be seen that it is impossible in practice to separate the two.

The chief difficulties in this type are:

1. Securing reliable data, discriminating between opinion and fact.

2. Selecting relevant material, and distinguishing between useless and unnecessary details and facts and factors that are really important.

3. Relating facts observed and results measured to peculiar conditions, in the school or locality; i. e., interpreting conditions and results with reference to local needs and conditions.

4. Selecting standards of comparison that are valid for the particular school.

5. Distinguishing between facts or conditions closely related in time and place and causal relationship.

6. Describing accurately and adequately the facts and conditions investigated.

In this type of investigation very great care must be taken at all stages. Many otherwise admirable studies have been made valueless by lack of care in securing reliable data. Facts must be obtained; mere opinions alone will not suffice, and such opinions as are considered must be evaluated with careful discrimination. It often takes much time and persistence to get at the real facts, but unless this can be done the investigation is worthless. Great care must also be taken in interpreting facts and conditions and especially in forming conclusions about the cause of a certain effect. The best scientists are often led astray in this particular.

This is illustrated by the commonly accepted statement by classicists that Latin provides mental training superior to that of any other subject. They base their conclusion upon this unquestioned fact. College students who have taken two or more years of Latin in the secondary school attain, on the whole, higher scholastic standing than those who did not take Latin in the secondary school. There is

${ }^{14}$ U. S. Bur. of Educ. Bul. 1924, No. 9.

${ }^{15}$ Columbia University Teachers College Contr. to Educ., No. 66, 1914.

10 O'Brien, Francis P: The high-school failures (Columbia University Teachers College Contr. to Educ., No. 102, 1919). 
no dispute about the fact as stated. The difficulty is regarding the validity of the conclusion. The question is this, Was the cause of the superior scholastic standing of the Latin students due to the Latin they studied? Are there no other factors that may have caused this? On investigation it is found that as a group the Latin students in our secondary schools are of a higher intellectual type than the non-Latin students. This fallacy of selection tends entirely to vitiate the conclusion. It does not prove that Latin was not a cause, nor does it prove that it was the cause.

Constant care must be exercised by everyone to avoid this kind of mistake. In this type, as in every other involving the use of statistics, the investigator should thoroughly familiarize himself with the approved statistical method. It should also be said that the exercise of plain common sense will often enable one lost in the maze of statistics to find his way out and to avoid absurd statements. Not long ago it was reported that two-thirds of all the graduates of $\mathbf{X}$ high school had failed in a certain college; this was compared with the record of $\mathrm{Y}$ high school, where only one-third had failed in the same institution. On investigation it was found that only 3 graduates of $\mathrm{X}$ high school had attended the college and 2 of them had failed. While in the case of the $\mathrm{Y}$ high school, $60 \mathrm{had}$ entered and 20 had failed. Query: Which was the better high school? Can we tell from the data presented?

Another danger, all too apparent in many statistical studies, is that of taking the average, median, or mode as an adequate description of the achievement of a group of students. Suppose two classes in algebra are being compared, and tests are used to measure the achievement of the two groups. The achievement scores of the two groups were as follows:

\begin{tabular}{|c|c|c|c|c|c|}
\hline & ass 1 & Class 2 & & $\operatorname{sss} 1$ & Class 2 \\
\hline $96-100$ & 1 & -- & $66-70_{-}$ & 4 & 6 \\
\hline 91-95_-_- & 2 & -- & $61-65$ & 4 & \\
\hline $86-90 \ldots$ & - & 1 & $56-60$ & 2 & \\
\hline $81-85$ & - & 2 & $51-55$ & 2 & \\
\hline $76-80$ & 3 & 2 & $46-50$ & 1 & \\
\hline $71-75_{-}$ & 5 & 5 & $36-40$ & 1 & \\
\hline
\end{tabular}

It will be seen that the average achievement is the same for the two classes, but in spite of this the two classes are essentially different. Class 1 is very irregular, having some who have high achievement and others who are very low. Class 2 is much more regular. The irregularities of class 1 are very significant, and the cause should be carefully investigated. In both cases the entire distribution should always be shown. If the attempt is made to judge the efficiency of the teachers, it might be found that the methods employed by the teacher of class 1 were more effective in stimulating the comparatively few 
who were very bright and not so efficient for the other students. "The teacher of class 2 might be holding back the bright ones and spending most of the time on the dull ones. Whatever the causes may be, the only safe procedure is to take the entire distribution of the class into consideration. Taking the average serves only to obscure the significant things.

Possibly the most difficult phase of a survey investigation is obtaining data covering a series of years. It can not be too strongly urged that records be carefully kept on all phases of the work of the school and as carefully preserved. For example, we should like very much to know what effect the junior high school has had upon school enrollment, elimination, and overageness in each grade. It is practically impossible to secure any. reliable data on these points because of the lack of definite records before the introduction of the junior high school and after. Principals and superintendents should always be careful to make adequate records and preserve them.

The case method of investigation.--One of the methods of investigation that has come into general use within the past few years is the case method. This method has been developed mostly in certain phases of social work and has arisen because of the difficulty of securing reliable data regarding individuals and because of the complexity of the problem of diagnosis. It has come to occupy a very important place in education because every educational problem is a social problem and sooner or later must deal with individuals. At present it is used most frequently in so-called problem cases; that is; in the study of students who for various reasons are not properly adjusted and in consequence cause trouble or are likely to drop out of school. While these problem cases come up first for consideration, there is every reason to believe that the same methods may be used in studying other children and in diagnosing their problems.

The following outline of the case method is adapted from the discussion by Morrison: ${ }^{17}$

I. Symptoms.-The first step is always to get at the facts that indicate that he is a problem case; not his history but the symptoms that have been noted. This involves finding his chronological age, the marks received in various sub. jects, instances of misconduct, latenesses and absences from school, etc.

All statements must be actually verified. They must be taken from school records when possible and only first-hand information accepted. The information thus obtained will often be sufficient to show that the case is not a problem one at all. Care should be taken here to exclude all that does not have to deal with present symptoms. History is valuable only as it throws light upon the causes of symptoms, but when gathering data on symptoms history should be excluded. When the data are all in they should be written up carefully and summarized.

\footnotetext{
17 Morrison, Henry C.: The practice of teaching in the secondary school, pp. 618-639 (University of Chicago Press, 1926.) See also Reavis, W. C.: Pupil adjustment in junior and senior high schools. (Heath, 1926.)
} 
II. Examination.-With the symptoms noted, more precise information regarding the case is obtained by various tests and examinations. These are, of course, selected with reference to the needs of the particular case. Some of these are here given:

A. Psycho-physical.

1. Vision-normal.

2. Hearing-normal.

3. Coordination (neuromuscular) -no good tests are available but careful observation will give helpful data.

B. Health.

4. Speech-normal.

1. Vital index (height-weight ratio).

2. Nutrition.

3. Teeth.

4. General physical condition.

C. Educational.

Standard tests of various kinds suitable to the grade of the pupil. These are to be used to discover any fundamental weaknesses in his previous training and also to check up on the marks he has received.

D. Mentality.

General intelligence test.

It is best to give several types in order to avoid accidental results.

III. Health and physical history.-Tery careful and exact information should be obtained not only of serious ilinesses, scarlet fever, measles, etc., but of other illnesses and operations for adenoids, tonsils, and any accidents that may have affected the health or resistance. If possible, a complete record of growth in height and weight and physiological maturity should be obtained and carefully recorded.

IV. School history.

A. Promotions.

B. Kind of work done.

C. Changed location-home and school.

D. Quality of schools attended.

E. Relation with individual teachers.

V. Family history.

A. Ancestry, parents, brothers and sisters, nationality, mental and criminal history, etc.

B. Economic status and history.

The previous and present financial and economic situation of the family.

C. Cultural resources of the home.

Education and training of parents, books, music, and cultural atmosphere of the home.

D. Relation within the home-with parents and brothers and sisters.

E. Attitude of parents toward society.

F. Adjustment of parents to American standards.

G. Control exercised by parents of children-

Kind and amount of control.

VI. Social history and contacts.-The pupils' social background outside the school and the home.

A. Church and Sunday school, Boy Scouts, etc.

B. Associates.

C. Summer camps...

D. Gang affiliations.

E. Abnormal sex history.

F. Court record. 
VII. Diagnosis.-This is the working hypothesis of the cause or explanation of the symptoms or the problem and results from a careful analysis of all the data obtained. It is not necessarily delayed until all the evidence is in, for guesses or hypotheses are actually being made and leads followed up at many stages, but the final diagnosis is not actually made until the evidence is in. Possibly the better statement would be that every guess or lead is followed until the worker is reasonably sure from the evidence that it is correct.

VIII. Treatment.-Out of the diaghosis grows the definite systematic treatment. It often happens that the treatment shows that the diagnosis was not correct. In this case we must go back for further investigation. In one sense the treatment may be considered as a step in verification of the hypothesis; in another it is itself a guess or an hypothesis set up as a possible remedy that itself needs verification by the final step.

\section{THE QUESTIONNAIRE}

The questionnaire method has been so generally used and so often misused that special consideration will here be given to it.

In the first place let us remember that the questionnaire is often a lazy man's method of getting alleged information that could be much better obtained in some other way. It is easy to sit down in the quiet of one's study and make out questions for some one else to answer. But such a method is very wasteful of the time and energy of the one to whom it is sent and is frequently wasteful of the time of the maker, for these questionnaires not infrequently find their wa $\vec{y}^{2}$ into the waste-paper basket, and many of them should. One has no right to take the time of some one else in answering questions when he himself can find the answer elsewhere. Nor, on the whole, can he consistently ask some one to spend his valuable time in work that will not presumably prove of value to him or his school. After he has decided upon the data he wishes, he should search through all available material to see whether these data can not be obtained through printed reports. If they can and he does not have the reports, he should send for them and get the data for himself. If the data given in the reports are not in the exact form in which he wishes them, he should change his own plan to fit the form used, where this is possible.

When he has exhausted all available material and feels that he must resort to the questionnaire method, let him observe the following directions and suggestions:

1. Make the questionnaire as brief and concise as possible. Onepage questionnaires are much more frequently answered than those of 2,3 , or 4 pages.

2. Organize it so that it can be answered by checks or by the insertion of a minimum number of words or figures.

3. Be careful of the spacing. Leave enough space for the answer.

4. Ask only for the information actually intended for use. The greater part of many questionnaires is never used and serves merely to clutter up the study. 
5. Formulate each question so that it will have identically the same meaning to everybody who answers it; and, if necessary, give specific definition of terms.

6. Questionnaires should ordinarily call for facts, not opinions. Such questions are more frequently answered, take less time of the one who fills them out, and are more reliable.

7. When judgments or opinions are asked, the questions should be so framed as to exclude dogmatic answers based on enthusiasm and opinions, and to assure reflective thinking. So far as possible objective evidence for judgments should be called for. Examples of two possible methods are here given in order to make this clear. The general object is to find the opinion of teachers on the following problem: "Should 14-year-old pupils of high intelligence be promoted into the junior high school even though they may not have completed the work of the sixth grade?"

$\Delta_{\boldsymbol{J}}$ First form. - "Should 14-year-old pupils of high intelligence be advanced into the junior high school regardless of their mastery of subject matter?") Such a question if submitted to a faculty would ordinarily be answered in the negative, because of the shock to schoolmaster attitudes, and accordingly should be avoided.

〜 Second form.- "Assuming that reasonable facility in reading the seventh grade mathematics books, seventh grade history books, seventh grade science books is essential to success in the seventh grade; and assuming that certain abilities in computation, spelling, penmanship are essential to success in the seventh grade, the question is: Is anything else essential to success in the seventh grade? Name such knowledge and skills as are necessary to success in the seventh grade."

"Assuming reasonable facility in the above-mentioned knowledges and skills, the question is. Should pupils who are 14 years of age, of high intelligence, be promoted regardless of whether they have completed the work of the sixth grade?" With this wording of the question there could probably be more reflective thinking as a basis for answering the question, and the conclusions would be, therefore, more valid than those based on the first form.

8. Before sending out any questionnaire it should go through the following stages:

(a) Very careful formulation by the author and arrangement in the form to be used.

(b) Submission to some expert for advice and correction.

(c) Try-out on teachers or others not primarily concerned-disinterested persons.

(d) A try-out of the revised questionnaire on a group as nearly like the ones to whom it is to be sent as possible. These try-outs will often show the in- 
accuracies of statement; the equivocal questions, and other undesirable features that can be corrected before the questionnaire is actually sent out for replies.

9. Be sure that each copy is clear and readable.

10. Always state clearly the purpose of the investigation.

11. Be sure that the investigator's name and address are clearly given on the questionnaire.

12. Provide a place for the signature of the one who fills out the questionnaire, together with his position and the date of filling it out.

13. Provide an extra copy so that the principal furnishing the data may have on file in his office a copy of the data collected.

14. A self-addressed envelope inclosed with the questionnaire will often bring good results.

15. Send a copy of the result of the investigation to each one who fills out the questionnaire.

\section{REPORTING RESEARCH}

After the investigation has been made comes the report or writing up the method and the results. This is very important. Many invaluable research studies make no contribution and do not affect educational practices either because they are never reported at all or because of faulty, inadequate descriptions. Consequently, great care should be taken in reporting all educational research.

In general, the report should be of such a nature as to give the reader a clear idea of the problem, the methods of procedure, the limitations, the data used, and the conclusions. For convenience, the following outline of desirable procedure is given:

(a) State clearly the purpose and limitations of the investigation. This constitutes not only its scope but also its contribution in the field where there have been other researches.

(b) Describe the methods, sources used, and mechanics in the investigation.

(c) In the body of the report include the discussion, tabulation, and graphic representation of the data of the research.

$(d)$ State the findings, conclusions, and recommendations as far as the research warrants.

(e) Place in an appendix any material that is illustrative or explanatory and is not needed in the body of the report.

(f) Reports should include a complete bibliography of all sources used. This should include careful annotations indicating the nature of each source. The items of the bibliography should be properly classified and systematically arranged. 
(g) As a general rule, a report should have a table of contents, a separate list of tables, charts, and diagrams, and, when of considerable length, an index.

\section{SUMMARY OF SUGGESTIONS AND DIRECTIONS}

1. Examine your school administration, curriculum, methods, and personnel to find some outstanding difficulties or inadequacies that will serve as research problems.

2. Select a problem that will make a difference when it is solved, the solution of which will tend to improve practices in the school.

3. Investigate carefully to see what scientific research has already been done on the particular problem which you have selected. It may have already been solved, but even if it has, other similar studies might well be made to test the conclusions of the studies already made. If it has not been solved, such an investigation will often give valuable suggestions regarding methods of procedure.

4. Before beginning research on any problem, think it through carefully, define it clearly, relate it to the larger problem of which it is a part, and formulate it definitely, subject, of course, to revision.

5. After you have selected a problem that looks promising, obtain the criticism and advice of some expert in the field with which you are dealing before actually undertaking it.

6. Many large problems should be broken up into units, each unit covering a specific phase of the larger problem. In this way. the problem is made more specific, and each unit is narrowed down to a small enough field so that it can be attacked directly. For your first study select as simple a problem as you can find.

7. Consider and evaluate all possible methods of attacking your problem before determining upon the procedure which you are to follow. One method of attack often brings quicker results; another, results that are more accurate. For your particular purpose, which is the best method to follow?

8. Define and state your technique so clearly that it can not be misunderstood, and so that some one else could duplicate it and thoroughly check the results by repeating your investigation in a different situation.

9. The method of procedure or attack should be carefully outlined. If statistical calculation is involved, it should be according to accepted mathematical procedure.

10. In the minor issues that arise, do not lose sight of the major problems.

11. When making comparisons, be sure that the data used are comparable. 
12. Differentiate clearly between what is fact and what is mere opinion.

13. When opinions are given, they should be signed by the people who contribute them.

14. Exercise great care in the use of the questionnaire method; unless carefully safeguarded it will not secure results that are trustworthy.

15. Avoid the error of drawing general conclusions from data that are inadequate.

16. In many studies all the educational outcomes must be taken into consideration. It might not be sufficient to consider only one outcome in determining the effect of a particular method of procedure.

17. If there are weaknesses in your method of attack, point them out; if you worked under limitations, point these out; state what possible inaccuracies there may be in your findings. Honest conclusions result only from honest consideration of all the facts and conditions.

18. Remember that all scientific conclusions are tentative; at best they are hypotheses that will, it is true, furnish the basis for action, but must be modified or rejected upon evidence of their inadequacy.

19. Be sure to test your tentative conclusions by practical situations and modify them in such a way as to secure practical results.

20. If in a position where this is possible, see that the solution is made a permanent part of the work of the school so that the improved results may be actually secured.

21. In reporting your research consult the pamphlets listed in this bulletin and make sure that you use the forms listed as most desirable. Make use of graphic methods in your presentation whenever this will make the meaning more definite and clear.

\section{RESEARCH AGENCIES AVAILABLE FOR THE PRINCIPAL AND TEACHER}

1. National Committee on Research in Secondary Education. Chairman, J. B. Edmonson, University of Michigan; secretary, E. E. Windes, Bureau of Education, Washington, D. C.

This committee is composed of representatives of the leading agencies in the country dealing with secondary education. It works in cooperation with the United States Bureau of Education and is always ready to assist in promoting educational research by suggestion and advice and by actual cooperation.

2. National Education Association, Research Department, John K. Norton, Director of Research, 1201 Sixteenth Street NW., Washington, D. C. 
This department is constantly engaged in research in the entire field of education and stands ready to assist research workers to the limit of its facilities.

3. Bureaus of research in State departments of education.

Wherever a State department of education has established bureaus of research, they can be relied upon for assistance. In many cases where there is no bureau of research much help can be obtained by communicating with members of the staff who are specialists in the various fields.

4. Bureaus of research in city school systems.

Many cities have now established bureaus or departments of reseavch in connection with their school systems. The directors of these bureaus are always ready to give friendly advice and criticism to research workers in cities where no research facilities are available.

5. Colleges and universities.

The principal and teacher can always rely upon professors of education and directors of research in universities and colleges to give needed advice and direction on various phases of research problems.

\section{BIBLIOGRAPHY}

\section{General References on Methods of Research}

1. Baldwin, Bird T. Educational research. U. S. Burean of Education. Bulletin, 1923, No. 42.

2. Buckingham, B. R. Research for teachers. New York, Silver, Burdette \& Co., 1926.

3. Chapin, F. S. Field work and social research. New York, Century Co., 1920.

4. Fleming and Pearce. Research in industry. London, Pitman, 1922.

5. Fling, F. M. Outline of historical method. Lincoln, Miller, 1899. (Out of print.)

6. Johnson, Allen. The historian and historicaì evidence. New York, Scribner, 1926.

7. McCall, W. A. How to experiment in education. New York, Macmillan, 1923.

8. Sears, J. B. The school survey. Boston, Houghton Mifflin Co., 1925.

9. Seashore, Carl E. An open letter to college seniors. Washington, D. C., National Research Council, 1925.

Contains very helpful advice on qualities necessary for a research worker.

10. Trow, W. C. Scientific method in education. Boston, Houghton Mifflin Co., 1925.

11. Williams, J. H. Graphic methods in education. Boston, Houghton Mifflin Co., 1924.

\section{Statistics}

1. Fisher, Irving. The making of index numbers. Boston, Houghton Mifflin Co., 1923. 2d ed. rev.

2. Garrett, Henry E. Statistics in psychology and education. New York, Longmans, Green \& Co., 1926.

3. Gregory, Chester A. Fundamentals of educational measurement. New York, D. Appleton Co., 1922.

4. Kelley, T. L. Statistical method. New York, Macmillan, 1923. 
5. McCall, William A. How to measure in education. New York, Macmillan, 1922.

5. Monroe, Walter S. The theory of educational measurement Boston, Houghton Mifflin Co., 1923.

7. Monroe, W. s., de Voss, J. C., and Kelley, F. J. Educational tests and measurements. Boston, Houghton Mifflin Co., 1917.

8. Odell, C. W: Educational statistics. New York, Century Co., 1925.

9. Otis, Arthur S. Statistical method in educational measurement. New York, World Book Co., 1925.

10. Rugg, Harold O. A primer of graphics and statistics for teachers. Boston, Houghton Mifflin Co., 1925.

11. - Statistical methods applied to education. Boston, Houghton Mifflin Co., 1917.

12. Thurstone, L. L. The fundamentals of statistics. New York, Macmillan, 1925.

13. Trabue, Marion R. Measuring results in education. New York, American Book Co., 1925.

14. Wilson, G. M., and Hoke, K. J. How to measure. New York, Macmillan, 1920.

\section{The Report}

1. Monroe, W. S., and Johnston, Nell B. Reporting educational research. University of Illinois. Bulletin, No. 25, 1925. Price 50 cents.

A 60-page bulletin giving detailed instructions for reporting all kinds of educational research. Invaluable for the research worker.

2. Reeder, Ward G. How to write a thesis. Bloomington; Ill., Public School Publishing Co., 1925. Price 90 cents.

A very useful treatment of methods of reporting research work.

3. University of Chicago. School of Education. Standard requirements for written work. Chicago, 1922.

An eight-page pamphlet giving definite directions for various forms of written work.

\section{Types of Research Studies in the Field of Secondary Education}

\section{Historical}

(1) Grizzell, E. D. Origin and development of the high school in New England before 1865. New York, Macmillan Co., 1923.

An examination into the origin and political, economic, and social influences that brought the high school into being in New England. The study ascribes the origin of the high school to American influences.

(2) Middlebrooks, John E. A history of the rise and fall of the academies in Tennessee. Master's thesis, George Peabody College for Teachers, 1923.

Points out the important facts about the academies in Tennessee; the purposes for which they were established; their means of support; their plan of organization and administration; their establishment and distribution; and the causes for their decline.

(3) Stoddard, James A. Background of secondary education in South Carolina. University of South Carolina. Bulletin No. 150, November 1, 1924.

A study from original sources of the development of secondary education in South Carolina. The colonial, post-Revolutionary, post-Confederate War, and postreconstruction periods are studied.

(4) Stout, John E. The development of high school curricula in the North Central States from 1860 to 1918. University of Chicago. Supplementary Educational Monograph No. 15, 1921. 


\section{Experimental}

(1) Brown, W. S., and Worthington, J. N. Supervised study in Wisconsin high schools. School Review, 32:603-12, October, 1924.

Describes an experiment designed to secure objective data on the comparative merits of supervised study and the class recitation plan. Interprets results as favorable to supervised study.

(2) Alderman, Grover H. Lecture method versus the question and answer method. School Review, 30:205-9, March, 1922.

Presents results of an experiment in an Iowa high school showing comparative values of lecture and question-and-answer method. Pupils ranked in higher quartile profited most by lecture method.

(3) Blair, Vevia, and others. An experimental course in senior high school mathematics. Teachers College Record, 22:394-414, November, 1921.

Outlines and analyzes content of an experimental course in senior high school mathematics developed in the Horace Mann School. The old and new courses in grade 10 were run parallel and comparisons made.

(4) Branson, Ernest P. An experiment in arranging high-school sections on the basis of general ability. Journal of Educational Research, 3:53-5, January, 1921.

Nine hundred pupils in the eighth grades and two classes in the high school of Long Beach, Calif., schools wele tested with the Otis group scale. Conclusion reached that the course of study should be examined with the needs of weak classes in mind, and that the granting of credits and the system of credit bookkeeping and program planning should be made elastic.

(5) Gates, Arthur I. A modern systematic versus an opportunistic method of teaching. Teachers College Record, 8: 679-700, April, 1926.

This study is especially helpful in the description of methods used to secure two groups that are equivalent and in the frank statement of limitations of results found.

\section{Philosophical}

(1) Cox, P. W. L. Curriculum adjustments in secondary schools. Chapters V-XIV. Philadelphia, Lippincott, 1925.

Illustrates a philosophical research checked by practices.

(2) Guthrie, Edwin R. The paradoxes of Mr. Russell. Lancaster, Pa., New Era Printing Co, 1915.

A study in the field of philosophy well illustrating the method.

(3) Suhrie, Ambrose L. The inductive determination of educational method. Warwick \& York, 1915.

(4) Waples, Douglas. An approach to the synthetic study of interest in education. Warwick \& York, 1921.

\section{Survey}

(1) Almack, John C., and Almack, James L. Administration problems connected with gifted children. Educational Administration and supervision, 8: 129-36, March, 1922 .

A study of superior students, juniors and seniors, in high schools of Eugene, Oreg. Fifty-one students selected out of 726. Army alpha administered, followed by Otis group test. Standard correlation between Army alpha and Otis was 0.765 (boys) and 0.659 (girls). Eight per cent of grades 7 to 12 were found superior. Concludes that it is easier to discover these individuals than to make satisfactory provision for them.

(3) Dement, Alice L. Values in extra-curricular organizations in the high school. School Review, 32: 40-48, January, 1924.

Presents data for 25 California high schools, showing the number of school organizations; the form of management employed; the purpose of each organiza- 
tion; the extent to which pupils participate; the accomplishments of the organizations; the approximate amount of time given to school organizations; and the cost of maintaining the organizations.

(4) Engelhardt, N. L., and others. Report of the survey of the public-school system of the town of Stamford, Conn. School year 1922-23. Teachers College, Columbia University.

Chapters of the report of interest in secondary education are: The teaching staff; secondary education; English in the high school; the teaching of mathematics; industrial arts; fine arts; vocational education and household arts education; Americanization classes for the foreign born; the present school plant; the city of Stamford and its school-building problem; the school-building program; school financing and school costs in Stamford.

(5) Moore, Harry H. Status of certain social studies in high schools. Washington, D. C., Government Printing Office, 1922. (U. S. Bureau of Education. Bulletin, 1922, No. 45.

A study based on an inquiry addressed to 13,000 high schools, including all four-year high schools and some of the large two and three year schools. More than 6,600 reports were received. Data collected on number of schools offering the various courses, methods of presenting courses, enrollment in each, criticisms, etc. Civics, economics, sociology, current events, and miscellaneous courses are studied.

(6) Northwest Association of Secondary and Higher Schools. Committee report, April 11, 1925. Student mortality in secondary and higher schools of the Inland Empire.

Analyzes data from 10 typical medium-sized high schools, with a total freshman enrollment of 10,805 pupils, for a four-year period, and from 16 higher institutions showing tendencies in elimination.

(7) Strayer, George Drayton, and Haig, Robert Murray. The financing of education in the State of New York. New York, Macmillan Co., 1923. (Educational Finance Inquiry Commission. Publications, vol. 1.)

An exhaustive analysis on the basis of statistical materials of the financial problem of education in the State of New York and resources for meeting the program.

(8) Survey of the schools of Wilmington, Del. Part 2. Washington, D. C., Government Printing Office, 1921. (U. S. Bureau of Education. Bulletin, 1921, No. 2.)

Contains chapter on secondary education. Status of secondary education; two high schools, one white, one colored; percentage school population in high school; holding power; retardation and failures; curriculums; teachers; administration and supervision; buildings and equipment.

(9) Clement, John A., and Clement, J. H. Summary of organization and administration of 40 junior high-school systems of Kansas. Educational Administration and Supervision, 8: 137-42, March, 1922.

Gives results of a questionnaire study of junior high schools of Kansas. Presents data on school population : enrollment, date and plan of organization; method of promotion; credit recording and classification of pupils; teaching periods per day; length of recitation, and plan of supervised study; experience, training, and salary of teachers; housing and control are introduced.

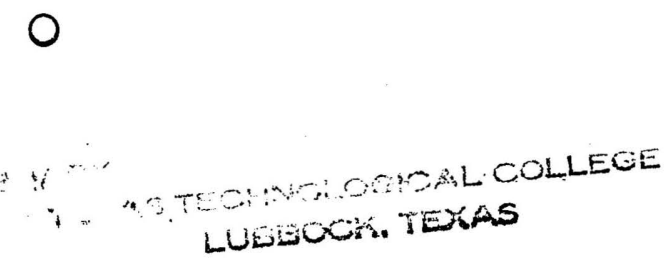





Photomount

Pamphlet

Binder

Gaylord Bros. Inc.

Makers

Syracusse, N. Y. PAT. JAN 21, 1908 


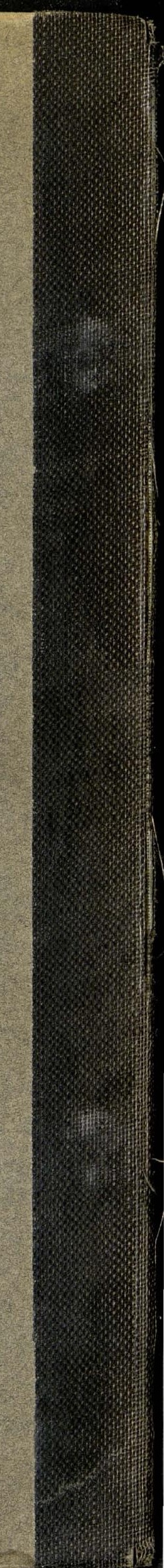

